Revista Internacional de Apoyo a la Inclusión, Logopedia, Sociedad y Multiculturalidad.

Volumen 5, Número 2, Junio 2019, ISSN: 2387-0907.DOl: https://dx.doi.org/10.17561/riai.v5.n2.11

\title{
Humanização e socialização em hospitais psiquiátricos: relato de experiência
}

(humanization and socialization in psychiatric hospitals: report of experience.)

\author{
Eudes Nascimento da Silva \\ Uninassau João Pessoa (Brasil) \\ eudesnascimento_@hotmail.com \\ Luís Augusto de Carvalho Mendes \\ Uninassau João Pessoa (Brasil) \\ contato@luisaugustomendes.com.br
}

Fecha recepción: 11-03-2019

Páginas: 129-141

Fecha aceptación: 20-05-2019

Resumo.

O presente relato de experiência consistiu em descrever as atividades desenvolvidas em um hospital psiquiátrico pelo campo da psicologia e como é promovido o trabalho interdisciplinar, com a finalidade de promover um tratamento humanizado e desenvolver a socialização de pacientes através de atividades de campo e oficinas terapêuticas promovidos pela instituição e grupos autônomos, muitos destes formados por estudantes que visitam a instituição promovendo dinâmicas e atividades recreativas, desenvolvidos nos espaços da instituição preparados para 0 desenvolvimento dessas atividades. Este artigo teve por objetivo descrever acerca das atividades desenvolvidas pelo psicólogo na assistência a saúde mental em hospitais psiquiátricos de acordo com as novas diretrizes da reforma psiquiátrica, a metodologia utilizada, abordava a discussão entre o referencial teórico e a execução das atividades realizadas durante o período de estágio curricular.

Palavras-Chave: hospital psiquiátrico; pacientes; saúde mental; estágio supervisionado

\section{Abstract.}

The present report of experience consisted in describing the activities developed in a psychiatric hospital in the field of psychology and how the interdisciplinary work is promoted, in order to promote a humanized treatment and to develop the socialization of patients through field activities and therapeutic workshops promoted by the institution and autonomous groups, many of them formed by students who visit the institution promoting dynamics and recreational activities, developed in the spaces of the institution prepared for the development of these activities. This article aimed to describe the activities developed by the psychologist in mental health care in psychiatric hospitals according to the new guidelines of psychiatric reform, the methodology used, addressed the discussion between the theoretical reference and the execution of the activities carried out during the period of curricular internship.

Key words: psychiatric hospital; patients; mental health; supervised stage 


\section{1.-Introdução.}

A Reforma Psiquiátrica e a luta antimanicomial, promoveram nos hospitais psiquiátricos o desenvolvimento de uma metodologia de assistência baseada nesses novos conceitos, buscando a desinstitucionalização. Assim, o presente relato de experiência foi organizado em um referencial teórico e na experiência prática, enfatizando a importância e a atuação da Psicologia em um hospital psiquiátrico da cidade de João Pessoa.

Este relato teve por objetivo descrever acerca da atuação do Psicólogo em hospitais psiquiátricos e a prática do estágio supervisionado desenvolvido, além da análise da vivência entre a prática e a teoria, também se fez necessário o estudo da fundamentação teórica, possibilitado assim um melhor entendimento entre as práticas desenvolvidas e a teoria respaldada, como também, possibilita ao leitor uma melhor compreensão do campo de estágio.

Enfatizando o referencial teórico, a assistência à pacientes psiquiátricos não pode ser reduzida ao estudo e tratamento das patologias, mas da promoção a socialização e humanização dos pacientes, para isso conta com uma equipe multiprofissional em saúde com profissionais de diversas áreas, dentre eles o Psicólogo.

O método utilizado para elaboração e conclusão do relato de experiência, se deu através do aporte teórico literário, a supervisão acadêmica da instituição de ensino e 0 suporte da equipe de saúde do local do estágio. No que refere à supervisão prática, estudos de casos, leitura de artigos cientifico e literatura científica de psiquiatria, grupos de estudos e a promoção de atividades práticas, didáticas, tais práticas vieram caracterizar o estágio em psicologia no hospital psiquiátrico.

A experiência de estágio em Psicologia em um hospital psiquiátrico na cidade de João Pessoa propõe aos leitores refletir acerca do referencial teórico proposto e as atividades desenvolvidas na pratica em instituições psiquiátricas, em um novo modelo de assistência a saúde mental, buscando a compreensão do sujeito em sua essência, possibilitando um tratamento humanizado e promovendo o bem-estar de pacientes e familiares, desmistificando muitos "mitos" acerca da assistência em hospitais psiquiátricos.

\section{2.-Hospitais psiquiátricos e rede substitutiva.}

No ano de 1728, Thomas Guy, criou em Londres, o que seria a primeira unidade psiquiátrica de hospital geral, denominado pela sigla UPHG, a LunaticHouse, no Hospital St.Thomas, onde o mesmo não deveria receber mais do que 20 pacientes por vez. Outras unidades compatíveis surgiram em muitos hospitais ingleses, não sobrevivendo, porém, além da metade do século XIX (Mayou,1989).

No início das Unidades Psiquiátricas de Hospitais Gerais (UPHGs) eram desenvolvidos planejamentos terapêuticos, integração à medicina clinica geral, com 
breves internações e rápido retorno à comunidade em que residiam, serviços de Inter consulta e de emergência, tiveram início em 1902, no Albany Medical Center, em Nova York. Outras unidades foram surgindo pouco a pouco ao longo das décadas de 1920 e 1930 (Bachrach,1981).

A principio, nos hospitais gerais, o processo de integração e de interação mútua entre a psiquiatria e outras especialidades foi realizada de forma gradativa, e distinta em três fases: deslocamento de pacientes psiquiátricos para enfermarias de psiquiatria, realização de Inter consultas e maior participação de psiquiatras em conselhos hospitalares. Esse foi um processo difícil, tendo que superar, até hoje, muitas resistências. Na América colonial, era rotina encaminhar os "loucos" para as, como assim conhecidas "loquerias" dos hospitais religiosos. (Larrobla Mendez, 1999)

No Brasil, a exemplo do que ocorria nos territórios espanhóis, o destino dos doentes mentais dependia da classe social a que este pertencia, podendo assim ter privilégios. Os mais pobres e menos afortunados eram encaminhados para as prisões ou Santas Casas, onde geralmente havia, nos porões, celas nas quais os doentes mentais permaneciam confinados (Larrobla Mendez,1999).

Em 1543 se instalou no Brasil, a Irmandade de Misericórdia, tomando como modelo a Casa-mãe de Lisboa, com a fundação da Santa Casa de Santos. E posteriormente, com surgimento de novos hospitais, tornou-se a base assistencial hospitalar da colônia. Muitos desses hospitais reservavam um espaço denominado ("casinha de loucos") para a acomodação de doentes mentais (Resende, 1987).

Os grandes hospícios começaram a surgir a partir do século XIX. Logo, até a década de 1970, a assistência a saúde mental foi gerida por grandes hospitais psiquiátricos, localizados em áreas afastadas dos grandes centros urbanos. Embora, as políticas de saúde em muitos países estavam voltadas para as doenças infectocontagiosas, para a atenção materna infantil e as deficiências alimentares, não se dava muita ênfase para a saúde mental (Larrobla Mendez, 1999).

No início da década de 1980, começaram a surgir muitos movimentos em defesa dos direitos civis e o fortalecimento de novas ideias referentes à atenção a saúde mental, logo que o surgimento de novas experiências realizadas em outros países, como na Itália, Inglaterra e Estados Unidos. Na América do Sul, a maioria dos programas nacionais de saúde mental foram implementados a partir dessa década (Larrobla Mendez, 2000).

No entanto, falta de segurança e de pessoal capacitado para trabalhar com essa demanda tem dificultado 0 atendimento de pacientes psiquiátricos agressivos e que necessitam de cuidados ambulatoriais. Além disso, a internação de pacientes psiquiátricos dependentes de álcool ou de drogas é muitas vezes recriminada ou marginalizada. A exceção fica por conta das poucas instituições que se especializaram nesse tipo de atendimento. 
Segundo a Organização Mundial de Saúde (OMS) não existe uma definição oficial para saúde mental. A saúde mental é um termo utilizado para descrever os níveis e possíveis distúrbios na qualidade de vida cognitiva, emocional ou comportamental. A saúde Mental pode incluir a capacidade de um indivíduo de apreciar a vida e procurar um equilíbrio entre as atividades e os esforços para atingir a resiliência psicológica. Admite-se, entretanto, que o conceito de Saúde Mental é mais amplo que a ausência de patologias relacionadas ao aparelho psíquico.

Saúde Mental consiste entre o equilíbrio emocional do sujeito e suas interações com 0 mundo exterior. Existem diversos transtornos mentais, com apresentações diferentes. Eles geralmente são caracterizados por uma combinação de pensamentos, percepções, emoções e comportamento disfuncionais, que afetam as relações sociais dos indivíduos. Entre os transtornos mentais, estão a depressão, 0 transtorno afetivo bipolar, a esquizofrenia e outras psicoses, demência, deficiência intelectual e transtornos de desenvolvimento.

Na prática, essa interpretação muitas vezes produz propostas generalizadas de intervenção que, por meio da supressão de comportamentos "inadequados", buscam 0 reparo e 0 melhoramento funcional dos sujeitos não ajustados com vista a reconduzi-los às regras do jogo social (não importando o quanto segregadoras ou excludentes estas possam ser). Além disso, subtraída da crítica das razões sociais e políticas do processo reabilitador, tal conceituação, quando posta em uso, opera à semelhança do modelo darwinista de funcionamento social, produzindo a seleção dos sujeitos considerados aptos à reabilitação e 0 abandono e desresponsabilização dos casos graves (Moraes e Castro-Silva, 2016).

\section{3.-Atuação do psicólogo no contexto psiquiátrico.}

A atuação do psicólogo não deve ser inspirada em um modelo médico, como historicamente a prática psicológica tem se presentificado no campo de saúde mental, que se pauta em uma perspectiva clínica individualizada, privatista e curativa assistencial, a qual trabalha, muitas vezes, com um sujeito idealizado e descontextualizado, na direção de adaptá-lo à ordem social vigente (Iglesias \& Avellar, 2016).

A lógica do apoio matricial requer do psicólogo da atenção básica uma disponibilidade em compor uma equipe interdisciplinar em saúde, que significa também permitir que o seu saber possa ser discutido e até questionado, a partir da necessidade e do desejo do usuário do serviço e bem como, um desprendimento, tanto no que diz respeito a sua abertura para a experimentação de outras atuações construídas no encontro, quanto à disponibilização do seu conhecimento ao outro, 0 qual, a partir do contato com este saber, pode, por exemplo, dar conta de melhorar sua relação com o usuário, qualificando sua escuta e potencializando suas práticas desenvolvendo planos terapêuticos mais eficazes (Iglesias \& Avellar, 2016). 
A coexistência entre esses modelos acarretaram no surgimento de determinadas dificuldades de diálogo entre ambulatórios e demais serviços de saúde mental, ocasionada pela grande quantidade de encaminhamentos, além do longo tempo de permanência dos usuários nos serviços ambulatoriais (Ministério da Saúde, 2001). Partes dessas demandas podem ser atribuídas à falta de novas pactuações e melhores diretrizes que possam possibilitar uma mais fluidez do funcionamento institucional entre os serviços de saúde mental nos municípios brasileiros.

\section{4.-Desenvolvimento do estágio.}

Conforme decreto federal, o estagio supervisionado para estudantes em formação devem seguir o seguinte:

Art. $1^{\circ}$ Consiste na supervisão qualificada desenvolvida no ambiente de estagio, a fim de promover a capacitação de alunos regularmente matriculados em instituições de educação superior, profissional, de ensino médio, da educação especial e concluintes do ensino fundamental, na modalidade de profissional da educação de jovens e adultos.

$\S 1^{\circ} \mathrm{O}$ estágio faz parte do projeto pedagógico do curso, além de integrar o itinerário formativo do educando. $\S 2^{\circ} \mathrm{O}$ estágio visa ao aprendizado de competências próprias da rotina profissional e à contextualização curricular, com o objetivo de desenvolver 0 educando para a vida cidadã e para o trabalho (LEI No 11.788, 2008).

A instituição de ensino deverá elaborar um projeto político pedagógico acerca das atribuições das atividades o campo de estagio, a fim de garantir ao estudante, na condição de estagiário, atividades e exercícios de acordo com sua área de formação. O estágio deverá ser acompanhado pelo professor orientador da Instituição de Ensino Superior. Sendo o estagio realizado fora da Instituição de Ensino Superior, também se faz necessário a supervisão de um profissional da instituição concedente, na modalidade de preceptor (Conselho Federal De Psicologia - CFP, 2013).

A Lei $n^{0} 11.788$ (2008) trata da fiscalização das relações entre instituições de ensino, estudantes e concedentes de estágios, entendendo-as (os) como parte do processo formativo. Outras normativas federais a respeito de estágio poderão ser produzidas. Resta, assim, a todas (os) as (os) envolvidas (os) no processo de estágio orientadoras (es), supervisoras (es), instituições de ensino concedentes, profissionais e estagiárias(os) - estar constantemente atentos à atualização da legislação e observá-la (CFP, 2013).

Portanto, considerando a importância dos estágios no processo de formação dos futuros (as) psicólogos (os) e zelando pela qualidade dos serviços psicológicos prestados à população, o Conselho Federal de Psicologia dispõe de normas sobre estágio (CFP, 2013). 
A formação do profissional enquanto estudante também é encontrada no Código de Ética da Psicologia (Resolução CFP no 10/2005), dispõe que: "O Código de Ética Profissional da (0) Psicóloga(0) delineia, para a sociedade, as responsabilidades e deveres $\mathrm{da}(0)$ Psicóloga(0), oferece diretrizes para a sua formação e baliza julgamentos das suas ações, contribuindo para o fortalecimento e a ampliação do significado social da profissão" (CFP, 2013).

Além do que já foi citado, pode-se colocar que este estágio em psicologia, de acordo com a Lei $n^{\circ} 11.788$ (2008), é um estágio do tipo obrigatório, determinado pelas diretrizes curriculares e projeto pedagógico do curso. Para além de ser obrigatório, ainda é um estágio externo, realizado em diferente contexto, fora da dependência da IES, de acordo com um termo de compromisso entre educanda (0), parte concedente do estágio e instituição de ensino, chamado pactuação de estágio (CFP, 2013).

\section{5.-Características da instituição.}

Segundo dados publicados no site do Governo do Estado da Paraíba em 2012, 0 Complexo Psiquiátrico Juliano Moreira, fundado em 1928, recebeu este nome em referencia medico psiquiatra Juliano Moreira (1972 - 1933) considerado o fundador da psiquiatria brasileira, sendo o primeiro professor universitário a citar e incorporar a teoria psicanalítica em suas aulas, além de ter representado o Brasil em congressos internacionais como os de Paris, Berlim, Lisboa e Milão nos anos de 1900, Juliano Moreira revolucionou as concepções e métodos da psiquiatria no Brasil, notadamente no que se referia à atenção às pessoas com problemas mentais.

À frente do Hospício Nacional dos Alienados do Rio de Janeiro, desenvolveu um método de tratamento mais humanizado, acabando com o manejo com pacientes enclausurados, desenvolvendo assim uma nova de tratar. Enfatizou e defendeu a ideia que fatores físicos e a exposição a fatores, tais como má higiene, a falta de acesso a educação, dentre outros fatores situacionais desencadeavam e agravavam doenças metais. Uma de suas principais lutas foi a reformulação da assistência psiquiátrica pública.

Uma de suas missões é prestar toda assistência necessária ao portador de transtorno mental, promovendo seu bem-estar e o retorno ao convívio familiar e da sociedade. Desde 2011, a unidade iniciou um processo de desinstitucionalização, e vem promovendo o retorno de pacientes moradores do serviço ao convívio com a família.

Outro trabalho importante desenvolvido no complexo psiquiátrico, no sentido de atender à Política Nacional e Estadual de Saúde Mental, é a diminuição no tempo de internação dos novos casos para que estes usuários também não venham a ser moradores institucionalizados. Para tal se faz necessário um trabalho interno de redirecionamento do modelo de assistência hospitalocêntrico, para um modelo voltado para a intervenção nas crises, nos surtos, mas que tem também a função de promover o retorno desses pacientes à comunidade e à família após a assistência necessária. 
O Hospital Psiquiátrico é um dos serviços ofertados pelo Complexo. Ainda integram a instituição o Ambulatório Gutemberg Botelho, que tem realiza atendimentos a usuários de segunda a sexta, diminuindo o tempo de internação, abrange usuários de todo o estado, o Espaço Inocêncio Poggi, e o Clifford - Pronto Atendimento de Saúde Mental, que realiza atendimentos de urgência, 24 horas.

O Complexo Psiquiátrico Juliano Moreira disponibiliza de uma equipe multiprofissional, formada por psiquiatras; psicólogos; fonoaudiólogos; assistentes sociais; enfermeiros; técnicos de enfermagem; cuidadores; nutricionistas; bioquímicos; odontólogos; médicos do trabalho e clínico geral.

O complexo possui 232 leitos psiquiátricos, sendo 132 leitos masculinos e 100 femininos; 12 são direcionados à internação de adolescentes com transtorno mental associado ou não à dependência química, sendo seis masculinos e seis femininos; 28 leitos são direcionados ao acolhimento de dependentes químicos adultos, dos quais 16 são masculinos e 12 femininos; 16 leitos são direcionados ao cuidado de pacientes geriátricos e moradores do serviço; 102 leitos são direcionados aos pacientes adultos do sexo masculino portadores de transtornos mentais não associados à dependência química ou casos especiais, associados à dependência; 74 leitos são direcionados à pacientes adultas com transtornos mentais associados ou não à dependência química.

\section{6.-Relato.}

Durante o estágio participasse e acompanhasse todas essas atividades, isso possibilita realizar uma observação diagnostica, observam-se o comportamento e a interação dos pacientes com as atividades e eventos sociais permitem ao psicólogo avaliar a evolução do processo terapêutico. Enquanto estagiário esses momentos propiciam uma vivencia mais "próxima" com os pacientes, sendo possível conhecêlos melhor, ouvir suas historias, o relato das suas vidas, suas experiência, como se sentem diante da enfermidade.

No Pronto Atendimento (P.A.) 0 atendimento é realizado pelo psiquiatra acompanhado pelo psicólogo, é realizado a escuta dos pacientes e dos familiares que 0 acompanham. Depois de uma observação de 72 horas, 0 paciente não apresentando uma melhora do quadro, o mesmo é encaminhado para internação nas clinicas terapêuticas, durante o período de interação o paciente e assistido por uma equipe multiprofissional em saúde metal.

Ao acompanhar 0 atendimento no P.A. vivenciei a experiência de identificar determinados sinais sintomas de determinadas patologias através dos relatos $\mathrm{e}$ queixas dos pacientes. A avaliação psiquiátrica nos possibilita 0 aprofundamento no conhecimento da psiquiatria e a psicofarmacologia que se faz necessário para 0 diagnostico. 
Os pacientes assistidos nas clínicas terapêuticas, geralmente apresentam quadros psicóticos, e muito destes, a psicose está relacionada com o uso de álcool ou drogas. Os meus atendimentos enquanto estagiário ocorreram com a devida supervisão na clinica masculina, antes de realizar o atendimento, era realizado um estudo do prontuário do referido paciente, o CID 10 e a medicação indicada, a partir desse momento o paciente era encaminhado a sala de atendimento.

Um dos casos acompanhados foi o do jovem Marcos, 22 anos, o mesmo veio transferido de outra instituição e apresentava comportamento agressivo, violento, delirante, alucinante, com possíveis diagnósticos de esquizofrenia. 0 paciente foi internado para que fosse possível realizar um melhor acompanhamento. Após iniciar o tratamento farmacológico, o paciente passou a apresentar um comportamento menos agressivo, nesse momento deu inicio ao acompanhamento psicoterapêutico, primeiramente ouvi o relato da equipe de saúde da clínica terapêutica, onde 0 mesmo estava internado.

Após ouvir 0 relato dos profissionais e cuidadores, passei a observar 0 comportamento do mesmo, conforme relato da equipe de saúde que acompanhava 0 caso, Marcos, após começar a ser ministrada a medicação, não apresentou quadros agressivos, no entanto, estava sempre isolado, não tomava banho, não saia do quarto, não interagia com os demais pacientes e tão quanto com a equipe de saúde, durante as minhas observações percebi que o comportamento do paciente condizia com o relato da equipe de saúde.

Seguindo com 0 atendimento ao paciente, na segunda semana 0 paciente demonstrava o mesmo quadro, realizei a leitura do paciente e em seguida solicitei que o mesmo fosse direcionado para a sala de atendimento, ao iniciar a escuta, 0 mesmo relatou que tinha algo para me falar, mas não lembrava o paciente não trouxe nenhum dado ou reflexão acerca dos motivos da sua internação, apenas relatou que estavam acontecendo "coisas erradas", mas não podia falar, se não iria ser morto, diante dessa e outras falas, comecei a trabalhar com 0 paciente a origem dessas ideias, no entanto o paciente apresentava um discurso delirante com fuga de ideias.

A escuta terapêutica apresentava evolução, tendo em vista as manifestações verbais e interação do paciente, embora delirante, através do delírio era possível elencar algumas representações que através das mesmas era possível traçar as estratégias de escuta. Levei o caso para a reunião semanal com o coordenador de psicologia juntamente com o psicólogo que estava me supervisionado no caso e outros psicólogos da instituição, apresentei o caso através da anamnese realizada, e da estratégia de escuta terapêutica. As reuniões são direcionadas para estudos de casos e discussão entre psicólogos e estagiários de psicologia.

Quando voltei para clínica, revisei o prontuário do paciente e constava que 0 paciente estava sendo medicado regularmente. No entanto, no atendimento seguinte, ao realizar a escuta, algumas vezes voltei para a questão da medicação, 
em um determinado momento o paciente respondeu que estava tomando a medicação e ao mesmo tempo gesticulou que não.

Tal comportamento está diretamente relacionado ao quadro delirante onde 0 paciente alega que estão tentando matá-lo, isso é evidenciado pelo fato do paciente relatar que não está tomando a medicação, pois a mesma esta envenenada. Isso caracteriza um quadro de delírio persecutório. A partir de então, discutindo com a equipe multiprofissional de saúde, se adotou uma nova estratégia para ministrar a medicação.

Na semana seguinte voltei a clinica para observar o comportamento do paciente, e me dirigi ao paciente para avaliar sua evolução de acordo com o plano terapêutico traçado, ele relatou que estava se sentindo bem, que queria apenas ir para casa e que se sentia um pouco incomodado com alguns pacientes que estavam ali. Esse comentário é relevante, tendo em vista que os pacientes apresentam comportamentos diversos.

O caso relatado acima é um dentre outros 08 (oito) casos que acompanhei que obtiveram altas e outros que continuam em tratamento na instituição, cada caso necessita uma estratégia diferente, pois são demandas distintas, sempre com auxilio da equipe multiprofissional de saúde e a equipe de psicologia, traçando melhores estratégias terapêuticas, o relato dos profissionais de outras áreas da saúde é importante para a coleta de dados acerca dos pacientes.

Minhas atividades enquanto estagiário eram desenvolvidas desde 0 atendimento clinico, até a promoção, excussão e acompanhamento das atividades desenvolvidas pela instituição, todas as atividades eram acompanhadas pelo psicólogo do setor e semanalmente eram reportadas e discutidas juntamente com o supervisor do setor de psicologia, nesse momento, eram discutidos casos atendidos, passadas as atividades que seriam desenvolvidas na semana seguinte, e o feedback das atividades realizadas.

\section{7.-Discussões.}

O estágio na instituição psiquiátrica teve inicio no mês de Julho, com termino em Dezembro de 2018, transcorreu no período de 10 horas semanais, em comum acordo com a instituição de ensino, sendo este obrigatório para a conclusão do curso conforme $0 \S 1^{\circ}$ da lei ${ }^{0} 11.788$ (2008) onde ressalta que 0 estágio faz parte do projeto pedagógico do curso, além de integrar o itinerário formativo do educando e§ $2^{\circ}$ da mesma lei determina que 0 estágio visa ao aprendizado de competências próprias da rotina profissional e à contextualização curricular, com o objetivo de desenvolver 0 educando para a vida cidadã e para o trabalho (Lei $n^{0} 11.788,2008$ ).

Mediante contrato de pactuação entre a instituição de ensino e a instituição do referido estagio, ficaram respaldado as responsabilidades das referidas instituições, 0 estagio aconteceu com a supervisão e a orientação de um psicólogo da instituição, 
como assim determina o Artigo $1^{\circ}$ (Lei $\left.n^{\circ} 11.788,2008\right)$ que consiste na supervisão qualificada desenvolvida no ambiente de estagio, a fim de promover a capacitação de alunos regularmente matriculados em instituições de educação superior, profissional, de ensino médio, das educações especiais e concluintes do ensino fundamental, na modalidade de profissional da educação de jovens e adultos.

O estágio prático e a supervisão pelo profissional da instituição, assim também foram realizadas a supervisão e as devidas orientações pela instituição de ensino, mediante o professor da cadeira de estagio supervisionado, onde se traçava as estratégias de estagio, como também o reporte sobre 0 desenvolvimento das atividades e a discussão de artigos de base acadêmica fundamentada o campo de estagio, as discussões com o professor da instituição acerca do estagio ocorriam semanalmente conforme grade curricular da instituição de ensino, como assim define o (CFP, 2013).

A instituição de ensino deverá elaborar um projeto político pedagógico acerca das atribuições das atividades o campo de estagio, a fim de garantir ao estudante, na condição de estagiário, atividades e exercícios de acordo com sua área de formação. O estágio deverá ser acompanhado pelo professor orientador da Instituição de Ensino Superior. Sendo o estagio realizado fora da Instituição de Ensino Superior, também se faz necessário a supervisão de um profissional da instituição concedente, na modalidade de preceptor.

A experiência enquanto estagiário permitiu vivenciar a pratica a rotina do psicólogo, suas atividades e técnicas do seu papel na instituição, essa experiência possibilitou sentir na prática o que até então era visto apenas na sala de aula. Portanto, considerando a importância dos estágios no processo de formação dos (as) futuras (os) psicólogas (os) e zelando pela qualidade dos serviços psicológicos prestados à população, o Conselho Federal de Psicologia dispõe de normas sobre estágio. (CFP, 2013)

O Sistema Único de Saúde (SUS), dentro do programa de Políticas Nacionais de Humanização, através de uma concepção psicossocial, desenvolveram o programa Clínica Ampliada que busca compreender o processo saúde-doença, promovendo um projeto terapêutico de que vá além do diagnostico e atendam as necessidades especificas de cada usuário (Ministério Da Saúde, 2008).

O papel da equipe multiprofissional era fundamental no processo terapêutico e na minha construção profissional enquanto estagiário, a troca de conhecimento e as orientações de outros campos da saúde, me possibilitou associar as técnicas adquiridas na sala de aula de acordo com as necessidades dos pacientes, na promoção de uma assistência humanizada. Os estudantes poderão fazer parte de equipes coordenadas por supervisores de diferentes profissões, ou poderão realizar as atividades de estágio em áreas emergentes ou em contextos em que não esteja presente um Psicólogo, desde que haja um supervisor responsável, da parte concedente (CFP, 2013). 
Enquanto estagiário de psicologia, tive participação em muitas atividades que eram direcionadas para as oficinas terapêuticas, no desenvolvimento e promoção de atividades de socialização os espaços disponibilizados pela instituição, tais como, campo de futebol, salas de artes e pintura, áreas destinadas a esportes diversos e a praça principal, onde os pacientes passavam boa parte do tempo, socializando com outros pacientes, profissionais e familiares. Nessa perspectiva, o trabalho prático em Saúde Mental já não envolve apenas psiquiatras, psicólogos e neurologistas, conta com a contribuição de diversos outros profissionais, como os da enfermagem, serviço social, educação física, pedagogia, entre outras áreas, que constituem a equipe multiprofissional.

A adequação da instituição a essa nova proposta, possibilita o desenvolvimento de um atendimento psicológico humanizado, voltado para a promoção da saúde e inclusão de pacientes psiquiátricos a partir das instituições psiquiátricas. Essas transformações refletem 0 trabalho que vêem sendo desenvolvido dentro da perspectiva da reforma psiquiátrica. Onde já na década de 60, no Brasil, iniciou-se a reforma psiquiátrica, que vinha a questionar o modelo atual, medicalizante, do tratamento da saúde mental em instituições psiquiátricas, denominado de movimento antipsiquiatrico, esse movimento se expandiu por vários países, com 0 intuito de restabelecer novos vínculos entre assistentes e assistidos; extinguir a reclusão e a repressão ao paciente, promovendo o direito a liberdade do paciente. Como também promover a interdisciplinaridade (Rodinesco,1986).

\section{8.-Considerações finais}

Participamos durante a graduação de muitas discussões com relação ao tema reforma psiquiátrica e luta antimanicomial, discutimos os métodos de intervenção em saúde mental e os desafios nesse campo, como também o papel da psicologia nesse contexto. O estágio em um hospital psiquiátrico, o qual foi fundado a mais de 90 anos, onde ao observar sua estrutura nos da uma ideia de como surgiram os manicômios, algumas salas e quartos com grades que datam da sua fundação ate às presentes transformações em um novo modelo assistencial, possibilitando vivenciar e participar desse processo de "remodelação" das instituições psiquiátricas.

Através da experiência do estágio foi possível aplicar a psicologia em consonância a outras áreas da saúde, o estagio possibilitou experimentar de forma bem próxima a atuação da psiquiatria, enfermagem, nutrição, clinica medica geral, embora cada uma com sua especialidade desenvolvam suas atividades paralelamente a fim de propiciar para os pacientes uma melhor qualidade de vida durante o processo de tratamento.

Enquanto aluno de psicologia, o estágio proporcionou uma experiência muito rica, onde pode ser assimilado o conhecimento teórico adquirido durante a graduação e a vivencia prática no campo, que além de proporcionar o conhecimento experiencial, a convivência com os psicólogos e o acompanhamento do preceptor da instituição, permite e promove um aprofundamento literário referente à demanda assistida pela 
instituição, patologias apresentadas, evolução do processo psicoterapêutico, suas praticas no que se refere à saúde metal, bem como sobre as transformações provenientes da reforma psiquiátrica.

Essa experiência além da vivência pratica da teoria e o conhecimento adquirido com os profissionais da instituição, leva a refletir sobre o quanto a psicologia e importante na assistência, promoção da saúde mental e na humanização dos pacientes com transtornos mentais.

$\mathrm{O}$ atendimento a pacientes com transtornos psiquiátricos parte desde a intervenção da farmacologia e o acompanhamento psicoterapêutico, o perfil dos hospitais psiquiátricos tem se adequado as propostas da reforma, o hospital o qual realizei 0 estagio desenvolvem diversas atividades dentro das perspectivas da reforma psiquiátrica, buscado desenvolver a socialização de pacientes durante o processo de internação e promovendo um tratamento humanizado de assistência multiprofissional, no entanto os hospitais psiquiátricos ainda são estigmatizados por um modelo asilar que promove dor e sofrimento a seus pacientes.

Faz-se necessário a realização de pesquisas nesse campo, para que se construa uma base teórica aprofundada com métodos, técnicas e resultados que possibilitem 0 desenvolvimento de programas de humanização e socialização de pacientes que sirvam como base para todas as instituições que atendem essa demanda. 0 desenvolvimento deste artigo resultou na proposta de relatar a experiência do estagio curricular, a fim de transmitir a comunidade acadêmica, as diversas variáveis a ser trabalhadas no processo da reforma psiquiátrica e as contribuições cientificas que podem ser desenvolvidas na área da saúde mental.

\section{9.-Referências}

Bachrach, L.L. (1981).General Hospital Psychiatry: overview from a sociological perspective. Am J Psychiatry;138 (7):879-87.

Campos, G.W.S., y AMARAL, M.A. (2007). A clínica ampliada e compartilhada, a gestão democrática e redes de atenção como referenciais teóricooperacionais para a reforma do hospital. Ciênc. Saúde coletiva [online], vol.12, n.4, pp. 849-859.

Campos, G.W.S., y Domitti, A.C. (2007). Apoio matricial e equipe de referência: uma metodologia para gestão do trabalho interdisciplinar em saúde. Cad. Saúde Pública [online], vol. 23, n.2, pp. 399-407.

Iglesias, A., y Avellar, L.Z. (2016). Os Psicólogos e o Matriciamento. Psicologia: Ciência e Profissão Abr/Jun. v. 36 n², 364-379.

Larrobla, C. (1999). Explorando as fronteiras da assistência psiquiátrica na América do Sul: o papel das unidades psiquiátricas nos hospitais gerais. Dissertação 
de mestrado. São Paulo: Unicamp. Disponível em: http://repositorio.unicamp.br/handle/REPOSIP/311441.

Lei n. 10.216, de 6 de abril de 2001. (2004). Dispõe sobre a proteção e os direitos das pessoas com transtornos mentais. Ministério da Saúde. Legislação em saúde mental: 1990-2004. Braília/DF: Ministério da Saúde. Recuperado em:

Lei n. 11.788, de 25 de setembro de 2008. (2008, 26 de dezembro). Recuperado em: 22 de agosto de 2008.

Mayou R. (1989).The history of general hospital psychiatry. Br J Psychiatry.155:76476.

Minitério da Saúde. (2001). Coordenação Geral de Documentação e Informação. Legislação em saúde mental. Brasília: Ministério da Saúde; 2001.

Moraes, R. C. P., y Castro-Silva, C. R. (2016). Sentidos e Processos Psicossociais envolvidos na Inclusão pelo Trabalho na Saúde Mental. Psicologia: Ciência e Profissão Jul/Set. 2016 v. 36 n³, 748-762.

Resende, H. (1987). Política de saúde mental no Brasil: Uma visão histórica. In: Bezerra, J.B. Cidadania e loucura: políticas de saúde mental no Brasil. Petrópolis: Vozes; p.1-73.

Rodinesco, E. (1986). História da psicanálise na França: a batalha dos cem anos. Rio de Janeiro: Jorge Zahar Editor.

Rotelli, F., Amarante, P. (1992). Reformas psiquiátricas na Itália e no Brasil: aspectos históricos e metodológicos. In: Bezerra, J.B, Amarante, P., organizadores. Psiquiatria sem hospício: contribuições ao estudo da reforma psiquiátrica. Rio de Janeiro: Editora Relume-Dumará;p. 41-55. 